\title{
Por que a ayahuasca? Da internacionalização de uma prática ritual ameríndia
}

\section{Anne-Marie Losonczy e Silvia Mesturini}

Tradutor. Alice P. Cidade da Silva

\section{(2) OpenEdition Journals}

\section{Edição electrónica}

URL: http://journals.openedition.org/aa/986

DOI: $10.4000 / a a .986$

ISSN: 2357-738X

\section{Editora}

Programa de Pós-Graduação em Antropologia Social (UnB)

\section{Edição impressa}

Data de publição: 1 dezembro 2011

Paginação: 9-30

ISSN: 0102-4302

\section{Refêrencia eletrónica}

Anne-Marie Losonczy e Silvia Mesturini, «Por que a ayahuasca? Da internacionalização de uma prática ritual ameríndia», Anuário Antropológico [Online], v.36 n. 1 | 2011, posto online no dia 09 novembro 2015 consultado o 28 abril 2021. URL: http://journals.openedition.org/aa/986 ; DOI: https://doi.org/ $10.4000 /$ aa. 986

\section{(9) $\odot \Theta \Theta$}

Anuário Antropológico is licensed under a Creative Commons Atribuição-Uso Não-Comercial-Proibição de realização de Obras Derivadas 4.0 International. 


\title{
Por que a ayahuasca? Da internacionalização de uma prática ritual ameríndia
}

\author{
Anne-Marie Losonczy \\ EPHE, IRIS, EHESS \\ Silvia Mesturini \\ LAMC-ULB
}

Este texto se articula em torno de duas questões. Como a ayahuasca ${ }^{1}$ veio a se destacar no seio da multiplicidade de plantas psicoativas descobertas quando do encontro colonial e pós-colonial das Américas? Como ela se tornou o portador privilegiado da circulação e da globalização das práticas espirituais e terapêuticas de origem amazônica desde então emblematizadas como representantes de uma espiritualidade pan-indígena?

Por meio de uma abordagem genealógica dos usos e das representações que as plantas psicoativas tropicais têm tido na cultura erudita euroamericana e nas sociedades amazônicas, tentaremos apreender as condições de emergência de novos espaços de interface simbolizados e alimentados pela ayahuasca. Nos indagaremos sobre o caráter performativo das noções de "patrimônio" e de "xamanismo" neste processo, tanto do ponto de vista amazônico quanto do meio terapêutico-espiritual internacional, que tem como figura central uma experiência pessoal, representada simultaneamente como a mais íntima e a mais universal.

O discurso e as práticas que acompanham a ayahuasca articulam assim, de uma maneira particular, a ligação entre crença e saber. A ayahuasca se torna o ponto de desencadeamento e cristalização de um trabalho experimental visando à pesquisa de continuidades de sentidos e traduções possíveis na interface entre fronteiras culturais historicamente construídas, que determinam o jogo assimétrico entre a categoria de "Ocidente" e de seu "Outro".

Através dos itinerários que a ayahuasca constrói e alimenta, é possível perceber os espaços de tradução e de negociação de sentido, o que pode esclarecer as razões e as modalidades de seu sucesso internacional, bem como o papel dos usos étnicos e territorialmente circunscritos desta substância.

O argumento desse texto se apóia sobre uma constatação: a decocção da ayahuasca, passando do uso local e regional à circulação nas redes globalizadas, funciona hoje como um ponto de condensação de negociações e de jogos de legitimidade que configuram modos relacionais particulares conectando múltiplos atores na interface entre sociedades indígenas, locais, e mundos urbanos latino-americanos e internacionais. Compreender o sucesso contemporâneo da ayahuasca significa, as- 
sim, abordar as continuidades culturais e sociais que construíram o canal histórico de contatos e adaptações, por um lado, entre os diversos povos amazônicos, e, por outro, entre o mundo amazônico e os sucessivos visitantes e os poderes externos.

\section{"Xamanismo" e ayahuasca: circulação e locais}

O fenômeno xamânico constitui hoje uma paisagem multissituada, desenhada pelos deslocamentos regulares à longa distância de especialistas rituais e praticantes bem como pela disseminação e reconfiguração constantes dos discursos e das práticas. Isto cria modalidades particulares de itinerância, pouco analisadas pela sociologia clássica das migrações, que parecem constituir uma figura emergente na "ordem das mobilidades" contemporâneas. (Cortés \& Faret, 2009). A mobilidade é aqui entendida como englobando, para além da circulação de indivíduos, a colocação em relação de lugares por meio da "transferência de bens, de capitais, de idéias ou de práticas [que] acompanham ou prolongam essas mobilidades e funcionam como outros tantos vetores de troca e de interação social" (Cortés \& Faret, 2009:9). A paradoxal característica central desta mobilidade é a circularidade de deslocamentos e a itinerância pluridirecional dos atores, acompanhadas necessariamente da circulação de objetos, de imagens e de representações. Estendendo-se entre várias regiões européias, bem como entre estas e as Américas, estes itinerários constroem rotas preferenciais em direção a lugares rituais considerados emblemáticos, epicentros de um campo cujas marcação e localização se definem e difundem graças a um vai-e-vem constante entre infraestruturas de acolhimento, usuários, especialistas e sua apresentação no cyber-espaço da web. Desde a recente entrada de práticas rituais e de objetos de inspiração ameríndios no mercado internacional das opções espirituais e terapêuticas, a referência ao "xamanismo" é mobilizada tanto por especialistas rituais quanto por aprendizes e usuários ocasionais ou assíduos de seus serviços.

Devido à sua visibilidade virtual e às relações que permite, o referente "xamanismo" se tornou hoje uma categoria de convergência no interior de um conjunto heteróclito de referências, freqüentemente designadas como New Age (Ghasarian, 2002; Hammer, 2001). Ele é associado ao mesmo tempo a várias técnicas psicoterapêuticas e a procedimentos divinatórios - tarô, runas, mediunidade... - e a discursos e projetos ecológicos centrados na preservação da floresta tropical, bem como a reivindicações de identidade étnica, em particular no continente americano. Tanto na rede virtual quanto nos itinerários de circulação de discursos e práticas, reunidos pelo referente xamânico, os indígenas da América Latina e as práticas rituais associadas ao consumo de substâncias vegetais psicotrópicas constituem dois emblemas centrais.

De fato, o fio condutor que percorre e unifica esses itinerários e lugares rituais 
é o acesso ao consumo ritualizado da bebida vegetal que se internacionalizou sob o nome quéchua "ayahuasca”, e que ganhou a reputação de ser um alucinógeno poderoso, indutor de visões de caráter místico. Esta representação da ayahuasca faz dela tanto o remédio por excelência para os mal-estares existenciais quanto a estrada real para uma nova relação com a "natureza", pela travessia das fronteiras entre o mundo "ocidental” e o mundo indígena. Assim, o mistério e o poder atribuídos à ayahuasca se apoiam sobre uma dialética particular da identidade e da alteridade, dialética que se constrói graças à oposição binária e emblemática entre o "Ocidental” e o "Indígena”.

O novo público "ocidental” das práticas ayahuasqueras de referência xamânica é principalmente urbano e proveniente das classes médias e altas, americanas e européias. Este público, oriundo do campo intelectual ou artístico, das profissões liberais e dos quadros dirigentes de empresas multinacionais, é frequentemente engajado no mundo das terapias em sentido amplo. A idade média se situa entre 30 e 50 anos e nele se observa uma maioria de mulheres, mas também, nos últimos anos, um interesse crescente do público masculino.

Este público se reúne em fins de semana ou em retiros de "medicina xamânica", também conhecidos como "oficinas de introdução ao xamanismo" ou "seminários de reencontro com a medicina das plantas." Estas reuniões se caracterizam pela centralidade da "tomada de palavra" das expectativas e experiências dos participantes, o que aproxima essas práticas daquelas dos grupos de terapia coletiva. Quando a ayahuasca está presente, estas “oficinas” se organizam em torno do ritual de seu consumo: sempre à noite, os participantes em busca de visões, reunidos em torno do xamã e dos aprendizes, muitas vezes trabalhando como tradutores, ingerem uma ou mais vezes a bebida, na escuridão carregada das canções do xamã e da desordem intestinal dos participantes. Essas tomadas ritualizadas são representados como uma experiência íntima esclarecedora e terapêutica. A "tomada de palavra" que as enquadra deve permitir aos participantes interpretar suas experiências comparando-as com a dos outros. O xamã, canalizando as interpretações e gerando a desordem eventual dos participantes durante as cerimônias, encarna aqui a figura de um líder espiritual e um conselheiro

Quanto às modalidades de circulação e de relocalização das práticas, elas se concretizam em diversos casos possíveis. Primeiro, as viagens iniciáticas individuais ou organizadas em grupo, às vezes por agências especializadas, aos lugares reconhecidos como emblemáticos da prática ayahuasquera na América do Sul, notadamente na região e na cidade de Iquitos, no Peru, conhecida como "a Meca da ayahuasca" no meio internacional de simpatizantes. Ao redor deste núcleo encontram-se disseminados os lugares-satélites que constituem sua periferia e que vão de Pucallpa, 
cidade central da etnia Shipibo no Peru, até Leticia, na Colômbia, na tríplice fronteira entre esta, Brasil e Peru. Entre estes lugares e a região de Iquitos, a circulação de xamãs e de usuários é constante.

Estas viagens suscitaram a criação de numerosas estruturas de acolhimento que permitem aos usuários e aos xamãs projetar e realizar itinerários de múltiplas etapas entre centros rituais diversos. Estes “centros xamânicos” estão situados em um ambiente de floresta, rodeados por largos terrenos, perto de uma estrada e próximos ao aeroporto da capital regional. Eles se constituem frequentemente de um conjunto de casas de madeira sobre palafitas, imitando certos tipos de arquitetura popular local, mas oferecendo um conforto de acordo com as necessidades do viajante estrangeiro (telas contra mosquitos em todos os cômodos, banheiros, chuveiros), onde ele será alojado e alimentado durante toda sua estadia. Uma equipe mestiça, localmente recrutada, assegura a manutenção, a preparação das refeições, a lavanderia, a vigilância e a assistência aos participantes da cerimônia em caso de mal-estar físico, frequente quando da ingestão da ayahuasca. Quanto ao trabalho ritual, este é realizado por especialistas que podem ser locais - indígenas ou mestiços - ou estrangeiros.

A associação estável de um xamã local com um ou vários de seus antigos aprendizes estrangeiros, transformados por sua vez em xamãs, parece de fato representar o caso que melhor garante o sucesso deste tipo de empreendimento. Quando o fundador de um centro é um xamã "branco", chamado regionalmente de gringo, a opinião local parece aceitar que ele aja com a autoridade de um "patrão" que emprega um xamã local, mesmo se tratando de seu iniciador. Não obstante, um xamã local pode também trabalhar de maneira independente, fundando seu próprio centro. Em ambos os casos, o status do xamã local será revalorizado uma vez que ele será percebido como em processo de emancipação econômica e social.

Os usuários, porém, originários de todos os países europeus, dos Estados Unidos, da África do Sul e da Austrália, formam também grupos de afinidade mais ou menos estáveis em seus lugares de origem. Eles periodicamente convidam os xamãs sul-americanos a seus países para conduzir rituais que podem durar vários dias. Um certo número de xamãs sul-americanos de diferentes origens nacionais se estabelecem também em diversos países europeus para se dedicar ali a um trabalho ritual regular.

Etnografar estas rotas significa privilegiar, em uma etnografia multissituada ${ }^{2}$, os lugares onde ayahuasca e xamanismo se entrecruzam pelo enquadramento do consumo da substância, mediante práticas rituais conduzidas pelos especialistas que mobilizam o referente xamânico. O consumo ritual da ayahuasca é igualmente central nos cultos populares de origem brasileira derivados do Santo Daime (Groisman, 1996 e 1999; McRae, 2000) cujo panteão de figuras sobrenaturais, 
longe de qualquer referência xamânica, é centrado nas figuras de santos do catolicismo popular amazônico. Por outro lado, contrariamente a outras plantas alucinógenas sul-americanas agora presentes na Europa e na América do Norte, cujo consumo pode ser recreativo, o consumo de ayahuasca é sempre associado a uma busca espiritual ou a um recurso terapêutico, ritualmente conduzido por uma pessoa que tenha uma função reconhecida de especialista. Pensar tal fenômeno unicamente em termos de "turismo espiritual" equivaleria a privilegiar o estudo dos deslocamentos em direção aos lugares de experimentação "religiosa”, enquanto que levar em conta as rotas do xamanismo internacionalizado nos leva a identificar igualmente os fenômenos de mobilidade, e às vezes de instalação, de especialistas latino-americanos nos locais de origem dos turistas. Além disso, a curta duração da "viagem turística organizada” não esgota a vastidão do fenômeno, que inclui também as viagens-de-busca de múltiplas etapas e as longas estadias de aprendizagem, ambos de duração indeterminada.

Entender a paisagem etnográfica que circunda o consumo contemporâneo da ayahuasca e a sua associação à categoria de "xamanismo" impõe um breve percurso histórico das condições de sua emergência no interior da cultura euro-americana e do contexto étnico e social da Amazônia.

\section{Substâncias psicoativas, contracultura e religião}

Desde os anos 1930, a relação das representações ameríndias do cosmos com as práticas rituais que incluem o uso de plantas de efeito psicoativo constitui o fio condutor da obra pioneira de Weston La Barre (La Barre, 1971) sobre os modos de consumo indígena e os efeitos visionários do peiote. Paralelamente, no rastro do movimento surrealista europeu, as plantas alucinógenas exóticas apareceram nas obras literárias e poéticas tais como as de Antonin Artaud e Henri Michaux. Tais obras criaram um novo gênero literário e um novo modelo estético, associando nas narrativas e poemas a viagem-de-desterro junto a grupos e culturas exóticas e a viagem introspectiva e visionária com a ajuda de plantas alucinógenas consumidas nestes locais.

Assim se consolida e se difunde a cadeia associativa entre "estados alterados de consciência” com a ajuda de plantas exóticas, visão alucinógena e viagem às profundezas interiores por meio do desterro cultural como fonte de criatividade estética e de compreensão do mundo.

Mas é a obra erudita de M. Eliade (1951) que coloca à disposição de um público culto internacional a categoria englobante de "xamanismo", no interior da qual os estados modificados de consciência se articulam em uma dimensão religiosa, terapêutica e espiritual imemorial, fundadora de todas as outras religiões. Com 
efeito, misturando um grande número de fontes etnográficas e históricas, Eliade unifica, em uma única figura conceitual, rituais de comunicação de um celebrante em estado de "êxtase" com entidades sobrenaturais, presentes em vários grupos étnicos espalhados pelo mundo. Esta categoria, construída em torno do estado de consciência modificada, que Eliade interpreta como via direta de acesso à experiência do "sagrado", pode assim integrar aquela, mais ampla, da "religião", com os qualificativos "arcaicos do êxtase": ela ocupa aí o lugar de religião-mãe, origem de todas as outras.

Esta dupla ancoragem conceitual do xamanismo, de um lado na temporalidade imemorial das origens de toda a humanidade, de outro na centralidade da experiência visionária como via direta para a transcendência, fazem dela uma prática atemporal e transcultural. Esse será o fundamento de sua performatividade enquanto categoria capaz de englobar numerosas práticas e representações da contracultura dos anos 1960 acerca da natureza, do Eu e da espiritualidade. Estas visam ampliar o campo cultural dos possíveis e subverter as fronteiras simbólicas e sociais estabelecidas por meio da busca de "estados alterados de consciência" induzidos pela absorção de substâncias psicoativas.

Nos anos 1940, o químico suíço Albert Hoffmann, no decurso de suas pesquisas sobre o fungo ergot nos laboratórios Sandoz, descobre e sintetiza o LSD. Mas é em 1954 que o grande sucesso editorial internacional da obra do escritor Aldous Huxley, As Portas da Percepção, descrevendo suas experiências de visão com a mescalina, populariza a experiência psicodélica e oferece sua primeira legitimação nos campos intelectual e estético (Carneiro, 2005:66), acessível a um público mais amplo.

Em 1957, o banqueiro americano Gordon Wasson faz sua primeira incursão ao mundo dos "cogumelos sagrados" em um povoado mazteca, Huatia, em Oaxaca, no México, sob a coruja da curandera, Maria Sabina. A publicação de suas experiências visionárias e cerimoniais levou ao local um bom número de viajantes hippies e fez do povoado uma das etapas reputadas das viagens "psicodélicas" internacionais (Langdon, 2005). Sua narrativa consolida a associação destas experiências a uma ritualidade indígena, ambas permitindo o acesso a uma nova dimensão espiritual.

Nos anos 1960, as experiências com substâncias psicoativas saem das clínicas e dos laboratórios, se democratizam e se espalham pela juventude americana, por intermédio de figuras como Timothy Leary, responsável por um programa de pesquisa sobre essas substâncias na universidade de Harvard, o qual se torna, através de suas aparições midiáticas, o guru do movimento hippie e contracultural da utilização coletiva, lúdica e espiritual de alucinógenos como a mescalina e o LSD. Paralelamente, entretanto, este último estará no centro do desenvolvimento de novos métodos psicoterapêuticos na Europa (S. Grof), no Canadá (H. Osmond e 
A. Hoffer) e nos Estados Unidos, para o tratamento de psicopatologias diversas.

Essas descobertas científicas e obras literárias pioneiras contribuíram conjuntamente para a emergência, alguns anos mais tarde, de uma corrente de pesquisa interdisciplinar (psicólogos, antropólogos psiquiatras, químicos, farmacêuticos, botânicos) sobre os efeitos visionários das plantas psicotrópicas exóticas, e posteriormente sobre produtos sintéticos, modificadores dos estados de consciência. A novidade dessa abordagem está na adoção de um ethos de auto-experimentação (Langdon, 2008) e na freqüente associação desta última à descoberta in situ de práticas rituais indígenas e de sua dimensão "sagrada".

A literatura e a antropologia não ficarão para trás. A publicação em 1963 da obra de dois poetas americanos beatniks, William Burroughs e Allen Ginsberg, intitulada TheYagé Letters, em que contam suas experiências com a ayahuasca na Colômbia e no Peru, sublinham o desterro cultural e mental como fonte de descoberta de novas dimensões estéticas e emocionais. A narrativa de um jovem antropólogo, Carlos Castañeda, The Teachings of Don Juan. A Yaqui way of knowledge, oscila entre o estilo descritivo da etnografia, aquele do diário íntimo e o da narrativa iniciática, e consolida a associação entre o efeito visionário das plantas alucinógenas locais e a mediação do saber de um "xamã" indígena, representado, mais que como especialista ritual, como iniciador e sábio, detentor da chave de acesso a "outras realidades” e poderes espirituais. O imenso sucesso popular de seus livros consagrou um gênero narrativo iniciático, cuja multiplicação torna-se rapidamente inseparável da "xamanização" das plantas psicoativas, bem como um modelo de relação, ele mesmo de tipo iniciático, com as "plantas de poder", tratadas como metonímias poderosas tanto dos rituais e saberes indígenas quanto dos Indígenas propriamente ditos. Tal sucesso emblemático não será em nada diminuído pelas reservas no meio antropológico universitário quanto à veracidade etnográfica da narrativa. A obra de Castañeda introduzirá o termo "plantas de poder" no vocabulário da prática xamânica ocidental nascente.

Em 1968, por outro lado, a reunião anual da poderosa AAA (Associação Americana de Antropologia) ratifica igualmente o impacto na disciplina da multiplicação de pesquisas sobre substâncias psicoativas (Langdon, 2005). Com efeito, numerosas pesquisas etnográficas e etnobotânicas nas sociedades ameríndias, com frequência acompanhadas de uma experimentação sobre si, se centram sobre o papel ritual da ingestão de plantas psicoativas e das visões que dela resultam nas práticas xamânicas locais, e sobre sua relação com as cosmogonias ameríndias (Dobkin de Rios, 1972). Mas esse interesse conduz também às primeiras coletas sistemáticas de conhecimentos indígenas sobre a fauna e a flora, que abrirão caminho à sua conceitualização em termos de "etnociência". Os fenômenos anteriormente considerados unicamente 
como "religiosos" ou "mágicos" - como a mistura, a preparação e a utilização de plantas psicoativas - serão progressivamente reclassificados na categoria de "saber". Essa polifonia conceitual que a antropologia desenvolve em torno da associação entre xamanismo e plantas alucinógenas será encontrada também no campo das representações e das práticas de um “xamanismo ocidental” em vias de expansão.

Assim, é durante os anos 1960 que se cristalizam a linguagem, a configuração de representações, assim como os pontos de cristalização de redes e itinerários que estabelecerão e alimentarão a ligação e as referências circulares entre plantas psicoativas, experiência visionária, rituais xamânicos, estética, psicoterapia e espiritualidade. Essa configuração e essas redes caracterizam-se pela porosidade e pela travessia incessante de fronteiras antes fechadas que estruturam o campo da cultura erudita: aquelas entre as disciplinas científicas, entre experimentação científica e experimentação pessoal e existencial, entre objetividade e subjetividade; aquela entre ciência e arte, antropologia e literatura, entre ciência e crença; aquelas entre passado e atualidade, sociedades "tradicionais" e "sociedades modernas". Esta porosidade das fronteiras contribui para redesenhar progressivamente os contornos da autoridade intelectual e filosófica em favor de especialistas rituais exóticos, emblematizados concomitantemente como "sábios" e "eruditos", metonímias dos "povos tradicionais". Os intelectuais-atores desta redefinição encontram, através das experimentações pessoais, o acesso simultâneo ou contextual a posições de autoridade em diferentes campos culturais e sociais - ser ao mesmo tempo artista conhecido, professor de universidade, pesquisador, psicoterapeuta, xamã... - , posições que se reforçam mutuamente.

Os termos utilizados para designar o efeito psicoativo de plantas selvagens e de produtos sintéticos como o LSD refletirão tal pluralidade crescente de abordagens e sua labilidade. O termo "alucinógeno", proveniente da linguagem farmacológica e psiquiátrica, domina os discursos até os anos 1960 e continua a ser utilizado em pesquisas para descrever o efeito visionário, considerado como o mais significativo entre os efeitos dessas substâncias. O qualificativo "psicodélico" foi criado em 1953 pelo psiquiatra canadense Humphrey Osmond para designar os efeitos de tais substâncias que, longe de serem associados à psicopatologia, são considerados em sua abordagem como psicologicamente enriquecedores, podendo ser preciosos aliados das psicoterapias. O movimento psiquiátrico, centrado na experimentação daí decorrente, produziu obras que descrevem seu desenrolar e benefícios terapêuticos das substâncias (Masters \& Huston 1970; C. Naranjo 1978, por exemplo). É também este termo que é em seguida adotado pelos movimentos contraculturais americanos e europeus dos anos 1960 e 1970 para qualificar tanto as experiências visionárias ligadas à ingestão lúdica e convivial destas substâncias quanto sua trans- 
posição para as criações artísticas - gráficas, musicais, literárias e cinematográficas - vistas como inspiradas na nova linguagem ética e estética assim revelada, em contraponto às convenções culturais clássicas.

O adjetivo "enteógeno", por sua vez, foi proposto por vários pesquisadores anglo-saxões (Ruck, Bigwood, Staples, Ott \& Wasson, 1979) para qualificar os estados induzidos pela absorção de plantas psicoativas. Criado a partir do grego antigo - entheos significa "inspirado, possuído por um deus" - este qualificativo permite dar conta do caráter "sagrado", "divino" supostamente atribuído a estas plantas em várias sociedades indígenas. Tal termo será notadamente utilizado em numerosas pesquisas antropológicas recentes feitas no Brasil sobre os cultos sincréticos em expansão do Santo Daime, União do Vegetal e Barquinha, que se constroem em torno do consumo ritual da ayahuasca (Dias, 1992; McRae, 1992; Soibelman; 1995; Groisman, 1999, entre outros).

Os anos 1970 sinalizam uma mudança de orientação política nos EUA: no quadro de uma política de repressão das redes de produção e venda massiva de substâncias psicoativas com toxicidade elevada, o uso e a experimentação clínica e universitária de plantas e produtos sintéticos psicoativos, doravante classificadas como "drogas", são proibidos. Essas práticas experimentais se refugiam então nos círculos informais e semiclandestinos, funcionando em rede, ao mesmo tempo em que tais disposições intensificarão as viagens dos usuários em direção aos grupos étnicos exóticos.

Mas o fim desse decênio será marcado pelo ressurgimento do interesse universitário pelo saberes rituais e botânicos exóticos, especialmente amazônicos, que criará novas modalidades de construção, de posicionamento e de transmissão do saber, que funcionarão como passarelas entre a universidade, os meios artísticos e as práticas indígenas. Pesquisadores como Terence McKenna, retomando idéias de La Barre, Eliade e Wasson, afirmam a existência de uma proto-religião "enteógena”, da qual os saberes e as práticas rituais indígenas seriam guardiães, e acentuam o papel das substâncias psicoativas na história das religiões.

Paralelamente, em 1979, Michael Harner, etnógrafo perspicaz dos Shuar do Equador, cria a Foundation for Shamanic Studies, que oferece programas de "treinamento" e de curas psicoterapêuticas "xamânicas". Em 1982, ele publica The Way of Shaman: a guide to power and healing, manual de práticas corporais e mentais que permitem ao leitor se tornar xamã. Em 1987, ele renuncia à sua cadeira na universidade para se dedicar exclusivamente, no seio de sua Fundação, à "preservação, estudo e ensino do conhecimento xamânico para o bem do planeta e de seus habitantes". 3

Diante da multiplicidade e da versatilidade rituais das práticas xamânicas de variados grupos étnicos, documentadas pelos trabalhos etnográficos, coloca-se a questão: qual é o xamanismo "preservado, estudado e ensinado" no Instituto fundado 
pelo antropólogo norte-americano?

Paul Jonhson (2003), examinando o itinerário “do Equador a Chicago" desse complexo e ideológico ritual concebido por Michael Harner, vê nele um movimento que separa as práticas xamânicas de seu contexto geográfico, social e étnico de origem para abrir sua passagem de um uso contextual e territorializado para um espaço universal e desterritorializado. Para Johnson, a inovação principal do xamanismo harneriano, ensinado na Fundação, em relação aos xamanismos indígenas, reside nesta universalização que distancia o xamanismo das contingências culturais e cosmogônicas, mediante sua visão como um conjunto de técnicas culturalmente neutras. Sua utilização não visa mais a restauração do equilíbrio cósmico e social, mas o desenvolvimento de poderes psíquicos pessoais. Esta individualização da prática xamânica resulta em fazer de cada praticante um xamã, terapeuta perpétuo de si. Johnson vê no xamanismo ensinado pela corrente harneriana uma nova forma ritualizada de autopsicoterapia, apoiada em um discurso de estilo pós-moderno que valoriza a mobilidade, a maleabilidade e a agentividade individuais.

Esses dois modelos de universalização dos saberes e práticas xamânicas, cada um construído por um antropólogo, serão performativos no interior de certos segmentos do campo intelectual institucional e artístico ocidental, bem como nas práticas e nos discursos de negociação e complexa tradução cultural que caracterizam as redes rituais internacionais, comumente chamadas "neo-xamânicas". O modelo de Terence McKenna universaliza o xamanismo, ancorando-o na temporalidade pré-histórica da humanidade, enquanto categoria intermediária entre religião e sabedoria. As culturas indígenas e seus praticantes ocupam no modelo um lugar particular: todos são guardiães e depositários de um saber e de uma prática religiosa intimamente articulada à conservação de uma "natureza inviolada" e nutriz da qual as plantas psicoativas, dentre as quais a ayahuasca são metonímia e emblema. As diferenças, as singularidades e os conflitos de interpretação cosmológicas e rituais são assim apagados para deixar emergir a imagem de uma cultura indígena genérica, patrimônio da sabedoria universal. Esta concepção abre um espaço de diálogo com certas idéias e valores ecologistas globalizados, com movimentos políticos indígenas de reivindicação de direitos coletivos, assim como com a nebulosa das espiritualidades New Age.

Por outro lado, o modelo harneriano de universalização do xamanismo, longe de naturalizá-lo e de associá-lo a um religioso imemorial, o inscreve, pelo contrário, na noção moderna de técnica, enquanto manipulação pragmática acumulável com outras e culturalmente neutra, visando a transformação do estado do sujeito. Tal perspectiva abre o xamanismo para as iniciativas internacionais de patrimonialização do imaterial, mas também para as correntes psicoterapêuticas 
em expansão, centradas sobre uma pragmática de mudança individual deliberada com vista a atender objetivos de promoção social.

Há, contudo, pontos comuns entre os dois modelos que, tornando-os permeáveis um ao outro, aumentam sua performatividade enquanto ideias-ponte entre universos de discurso diversos. O primeiro é a centralidade da auto-experimentação e a necessidade da passagem pela dimensão estética e sensorial na abordagem do consumo ritualizado de plantas psicotrópicas. Objetos e condutas rituais, vestimentas, pinturas e músicas aparecem tanto como sinais diacríticos da autenticidade e da eficácia do xamanismo quanto como meio de acesso privilegiado ao seu conhecimento. Esta perspectiva marca uma porção crescente das reflexões antropológicas recentes - sobretudo americanas e brasileiras - sobre os xamanismos indígenas e sobre a implicação experimental, corporal e emocional do pesquisador-observador na prática ritual. Esses questionamentos conduzem à redefinição de fronteiras entre objetividade e subjetividade na pesquisa científica, valorizando a experiência subjetiva como fonte de conhecimentos cientificamente válidos.

O segundo ponto comum se encontra naquilo que os dois modelos eliminam - por meios diferentes. Primeiramente, o contexto social e conflitos internos enquadrados pelos xamanismos nas sociedades indígenas, da mesma forma que as relações de dominação e de negociação política no nível regional e nacional nos quais essas sociedades se inserem. Tal obliteração encontra um poderoso eco nas representações e interpretações do xamanismo, expurgado de suas dimensões guerreiras e de agressão e reformulado em sabedoria ecológica planetária, representações que circulam nas redes da internet e sustentam novas formas ritualizadas de atuação (Mesturini, 2010).

Da mesma maneira, essa "moralização" (Calavia, 2009) constitui uma força poderosa na representação das práticas rituais xamânicas enquanto psicoterapia dirigida a grupos urbanos e internacionais. Mas os processos de universalização escamoteiam também as referências sutis das práticas xamânicas indígenas a cosmogonias complexas e diversas, presentes nos mitos, mas codificadas também na produção local de formas pictóricas e de música. Destacados do contexto social e da espessura cosmológica, os procedimentos rituais podem também se transformar em "técnicas" xamânicas, prontas-para-circular, sustentadas por elementos reduzidos e simplificados de representações cosmológicas heterogêneas. Em suma, tudo se passa como se uma das condições da circulação internacional de itens culturais e estéticos fosse a redução de seu enraizamento cultural a uma marca genérica "indígena" e o esvaziamento de seu contexto social de origem. 


\section{A ayahuasca e o caucho: história de uma circulação}

Mas quais eram os usos indígenas da ayahuasca antes da emergência de sua globalização? Relendo as etnografias das sociedades indígenas da Amazônia brasileira, Oscar Calavia Saez (Calavia Saez, 2009) constata a grande riqueza e variedade de plantas psicoativas - não necessariamente alucinógenas - utilizadas e combinadas por esses grupos, entre as quais a datura, bem como a fumaça e o suco de tabaco, a pimenta amazônica e outras plantas nem sempre identificadas. Em vários casos, a aparição entre elas da ayahuasca parece mais recente: ela é sempre utilizada misturada com outras plantas. De acordo com o testemunho das etnografias, o consumo indígena da ayahuasca surge sempre ligado às redes de troca regionais de saberes rituais e de substâncias que vinculam historicamente diferentes grupos indígenas. A existência destas redes, expandidas posteriormente aos colonos, foi corroborada e analisada pelos trabalhos de M. Alexiades para toda a bacia amazônica (Alexiades, 2009) e de Peter Gow (Gow, 1991) para a Amazônia peruana.

Os xamanismos indígenas que integram a ayahuasca atribuem um lugar privilegiado à "visão" como fonte primordial de aquisição de conhecimento e de controle sobre as entidades sobrenaturais. Esta orientação cria um campo xamânico interétnico: os cantos, os desenhos e os mitos que a ele são ligados circulam atravessando os limites lingüísticos e étnicos entre grupos. É esta centralidade da “visão" associada à ingestão da bebida que encontrará um poderoso eco na cultura euroamericana urbana, cada vez mais dominada pela produção e pelo consumo de imagens midiáticas.

Assim, bem antes de sua entrada no processo de internacionalização derivado da contracultura euroamericana, a ayahuasca já desempenhava o papel de "substância mediadora" (Calavia Saez, 2009) em uma mobilidade interétnica em escala regional. Numerosos historiadores e antropólogos documentaram sua utilização na vastidão da bacia amazônica e sublinharam que a plasticidade das representações associadas a esta bebida e ao seu consumo ritual fazia dela um suporte privilegiado para a circulação de objetos, de saberes rituais e de indivíduos (Calavia Saez, 2009; Gow, 1991).

A partir do início do século XX, o processo de deslocamento e de mistura dos grupos étnicos da Amazônia ocidental, já em marcha desde o século XVI, se intensifica através do sistema de habilitação, ${ }^{4}$ ligado à exploração ostensiva do caucho, cobiçado pelas indústrias européias e norte-americanas. O recrutamento sistemático de uma mão-de-obra não amazônica e o caráter itinerante do trabalho de exploração do caucho cria novos lugares de povoamento e de encontro interétnico. $\mathrm{O}$ acesso à ayahuasca, que aparece como um remédio eficaz contra males variados para essa população desprovida de quaisquer recursos terapêuticos contra as doenças relacionadas ao clima e à exaustão, abrirá seu uso para além dos quadros étnicos. A bebida seguirá assim os circuitos de troca ligados à exploração e às rotas comerci- 
ais e se introduzirá nos novos povoados e cidades regionais mestiços. A ayahuasca, disponibilizada em escala regional e transfronteiriça e reconhecida como remédio por numerosos colonos, nem por isso perde sua conotação de bebida misteriosa, objeto de fascinação e de terror, ligada à imagem colonial da "selvageria" indígena (Taussig, 1986: 90-100). As passagens e a instalação de xamãs de diferentes etnias, fornecedores da ayahuasca nas novas localidades extrativistas, se inscrevem, por sua vez, em uma tradição de origem pré-colonial de circulação interétnica de objetos, de saberes e de xamãs aprendizes.

A partir da segunda metade do século XIX, a ação evangelizadora das missões franciscanas, capuchinas e jesuíticas em diversas regiões da Amazônia se dirige contra uma grande variedade de práticas rituais étnicas, as tratando como um bloco homogêneo de inspiração diabólica. Esta estratégia contribui para uma homogeneização observável das práticas indígenas, mas também para sua adaptação ao novo ambiente social. Contrariamente ao pressuposto clássico em antropologia que atribui aos grupos indígenas geograficamente mais isolados um sistema xamânico "puro", estas práticas homogeneizadas de um “xamanismo de contato”, recentrado no consumo ritual da ayahuasca, retornarão aos povos da floresta aureolados com mesmo prestígio que possuem, a seus olhos, os objetos manufaturados urbanos, interpretados como signos do poder material dos "Brancos" (Gow 1999: 90-113).

Dos anos 1950 em diante, a ayahuasca, bem como as práticas e os especialistas a ela ligados, saem progressivamente da área amazônica segundo várias modalidades concomitantes. Eles chegam às capitais nacionais, sobretudo nos bairros periféricos, como "medicina dos pobres", para se verem progressivamente revalorizados como emblema de uma indianidade em vias de reconhecimento e integração no espaço jurídico e político da nação. Desde então, graças ao apoio militante de uma intelligentsia progressista, seu uso emerge em instituições universitárias nacionais e depois em meios ligados às ONGs internacionais que trabalham no continente. Paralelamente, os xamãs convergem em direção aos centros urbanos e às zonas que acolhem os estabelecimentos turísticos convencionais para propor seu saber-fazer a um público "ocidental” cada vez mais interessado. Vários deles atravessarão em seguida o Atlântico para serem recebidos nas grandes cidades do Norte.

Novamente, é ainda esse papel histórico de atravessador de fronteiras, mediador e suporte interétnico de práticas rituais, musicais, visuais e discursivas compartilhadas, que a ayahuasca continua exercendo, circulando doravante em uma rede expandida ao mundo extra-amazônico, não indígena, urbano e intelectual. Mas essa relação de intensidade crescente entre grupos indígenas e círculos urbanos e transnacionais, associada à inscrição do "xamanismo" no repertório New Age, também retornam aos xamanismos vernáculos. A representação não indígena dos rituais da ayahuasca em 
termos de "medicina" e de terapêutica está no fundamento de seu uso, central nos cultos neo-amazônicos em expansão como a nebulosa do Santo Daime brasileiro.

Por outro lado, no processo de sua deslocalização e expansão em direção a vários meios sociais internacionais, os xamanismos indígenas se simplificam e se reduzem: as facetas ligadas à gestão da hostilidade, à guerra, à predação e à feitiçaria tendem a desaparecer. Assim o mundo móvel e complexo dos espíritos, parceiros e adversários íntimos do xamã, tende a ser substituído pelo face-à-face entre a figura difusa e consensual de um Eu individual maleável e a ayahuasca, mediada pelo xamã. A relação ambivalente com o mundo animal e a predação é apagada: a onipresença única da ayahuasca aparece como sinal inequívoco de um processo de "moralização e vegetalização" - para retomar a elegante expressão de Oscar Calavia Saez - que afeta os xamanismos indígenas na sua deslocalização geográfica, cultural e social. Quanto à repercussão deste processo nas sociedades indígenas no Brasil, é possível observar, em diversos grupos, a adoção recente da bebida no contato dos neo-religiosos ayahuasqueros do Santo Daime, da Barraquinha e da União do Vegetal, como no caso dos Apurina do Acre (Lima da Silva, 2002). Outros intensificam o consumo ritual da bebida e fazem dela um signo diacrítico de sua "cultura", como os Kaxinawa.

\section{A ayahuasca-patrimônio}

Desde a conquista e o começo da colonização da América do Sul, a imagem européia da floresta tropical aparece alternadamente como uma materialização do Jardim do Éden ou do Inferno, imagens de inspiração católica. A partir dos anos 1960, a valorização do mundo indígena pela contracultura euroamericana é concomitante ao desenvolvimento progressivo de um indigenismo político latinoamericano que culmina na década de 1990. Ambos abrem caminho para uma recomposição da imagem da floresta, de seus habitantes indígenas e de seus produtos, enquanto último refúgio de uma diversidade natural e cultural a ser conservada.

No continente latino-americano, os anos 1980 são aqueles do reforço das reivindicações indígenas de direitos coletivos, tanto em nível nacional quanto nos fóruns jurídicos e ecológicos internacionais, onde a questão dos direitos das minorias se torna prioritária enquanto medida do "desenvolvimento durável” e de legitimidade internacional. Este contexto geral contribui para a adoção de novas Constituições em certos países, como o Brasil, a Colômbia, o Peru e o Equador, que se traduzem em políticas públicas de reconhecimento dos direitos territoriais coletivos e da diversidade cultural como parte integrante e patrimônio da identidade nacional. Desde então, debates jurídicos nacionais se cristalizarão em torno do consumo da ayahuasca, reforçando assim seu papel metonímico de signo identitário diacrítico ligado à Amazônia. 
Em 2008, no Brasil, vários centros neo-religiosos ayahuasqueros, com o apoio do estado do Acre, formulam uma demanda ao Ministério da Cultura para que o IPHAN (Instituto do Patrimônio Histórico e Artístico Nacional) reconheça seu uso da ayahuasca em contexto religioso como patrimônio cultural imaterial brasileiro. Paralelamente, em junho de 2008, o Instituto Nacional da Cultura do Peru declara os conhecimentos e usos tradicionais da ayahuasca nas comunidades nativas amazônicas como patrimônio cultural nacional peruano, em um documento que associa esta bebida à medicina tradicional indígena e à identidade cultural amazônica. No caso brasileiro, são os grupos ayahuasqueros recentes que tentam estabelecer sua legitimidade nacional e internacional enquanto "guardiães das tradições religiosas amazônicas”, visando ocupar assim o lugar do indígena no imaginário e na cena nacional. No Peru, a iniciativa da patrimonialização identitária da ayahuasca vem do Estado, que incluiu nela todos os grupos indígenas amazônicos, entre os quais alguns que não a utilizam. A bebida aparece nos dois casos tanto como metonímia e sinal diacrítico de uma indianidade selvática genérica quanto como ponte e marco entre o religioso e o saber terapêutico.

Assim, em 2010, no Brasil, onde o seu consumo ritual é legalizado, um grupo de trabalho constituído pelo Estado brasileiro e composto de representantes do governo, de pesquisadores e de dirigentes de novas "religiões da ayahuasca", como o Santo Daime, propõe a manutenção da legalidade do uso da ayahuasca em contexto religioso e ritual, mas apresenta uma "deontologia" que desaconselha sua ingestão por mulheres grávidas, menores e pessoas que apresentem sintomas psicopatológicos.

A expansão da ayahuasca aparece pois inserida na trama de interações e negociações complexas de grupos indígenas e mestiços da floresta com as sociedades nacionais. Contudo, os pesquisadores e as redes de ONGs e usuários internacionais desempenham um papel mediador e legitimador importante, fornecendo às duas partes uma língua polifônica na qual as propriedades eficazes da ayahuasca e a ritualidade de sua ingestão se traduzem em termos ao mesmo tempo identitários, jurídicos, terapêuticos e patrimoniais. Esta mediação coloca à disposição da multiplicidade de atores um campo semântico de muitas entradas que sustenta um esforço constante de tradução.

As práticas e os especialistas associados ao referente xamanismo-ayahuasca constituem uma fonte de visibilidade e de legitimação para certos grupos indígenas dos quais se tornaram emblemas. Estes grupos podem tecer e estabilizar mais facilmente ligações com organizações do mundo associativo internacional capazes de operar como financiadores potenciais, tais como ONGs, grupos espirituais e terapêuticos europeus e americanos. O xamanismos ayahusquero aproxima-se também, neste cenário nacional e internacional, do indigenismo político e do ambi- 
entalismo globalizado que construíram a imagem genérica do "Índio" como figura antropomorfizada do ideal ecológico. Estas conexões conduzem à elaboração de projetos de "desenvolvimento" relativos a diversos setores da vida econômica e social local. O vai-e-vem de informações textuais e visuais concernentes à construção de projetos e de microempreendimentos, da mesma maneira que os conflitos de interesses e de interpretação que suscita, servem-se frequentemente da internet e configuram um espaço virtual e movente de interação e discussão que afrouxa restrições espaciais e temporais.

\section{A ayahuasca-tradutora}

Nos lugares amazônicos emblemáticos do consumo turístico da ayahuasca (Iquitos, Pucallpa, Nauta, Leticia...) os critérios locais e aqueles do público "ocidental" concernentes à qualidade e à "autenticidade" do trabalho ritual xamânico não coincidem inteiramente, e essas divergências constituem o ponto de emergência de diferenças de interpretação irredutíveis ao compartilhamento voluntário e desejado de uma atividade ritual. Assim, ainda que a origem indígena do saber do xamã seja um critério essencial de prestígio aos olhos do viajante estrangeiro, para os atores locais a reputação adquirida na gestão de conflitos que se manifestam por ataques de feitiçaria recíprocos e contínuos entre xamãs aparece como o sinal indiscutível da competência xamânica. Se os viajantes aceitam como "autêntica" a ayahuasca proposta pelos “estágios" ou pelos “centros" que os acolhem, ainda que ela seja frequentemente comprada no mercado urbano ou preparada por não-xamãs, segundo o julgamento local a boa ayahuasca deve ser colhida na floresta somente pelo xamã, e a decocção tem ser preparada por ele.

O valor cobrados dos viajantes pela estadia e participação nas cerimônias pode variar, mas se torna frequentemente objeto de conflitos e de julgamentos contraditórios entre locais e estrangeiros. Esses montantes são expressos em dólar e oscilam entre 50 e 300 dólares por dia nos quadros de uma estadia em um centro, enquanto uma sessão isolada de consumo da ayahuasca pode variar entre 20 e 50 dólares. Nos casos de aprendizados de longa duração, os valores são objeto de negociações particulares entre o aprendiz e o xamã.

Essas circulações multidirecionais entre Norte e Sul reúnem pois em torno da ayahuasca indivíduos provenientes de grupos sociais outrora separados social e espacialmente. As categorias genéricas de "ocidental” e de "indígena”, avatares recentes de uma longa tradição colonial e pós-colonial de contato, constituem os pólos de um campo relacional que religa as Américas e a Europa, as capitais e os povoados e cidades na floresta (Gow, 1993). Este campo enquadra e domestica as diferenças culturais que emergem das situações de interação em torno da ayahuasca. 
O interesse amazônico pelo "ocidental”, localmente chamado de gringo, é feito do fascínio por sua tecnologia, da desconfiança face ao seu poder material e às vezes de desprezo. As diferentes cenas dos rituais ayahusqueros o colocam em contato com a imagem idealizada do "indígena" sustentada por aqueles que demandam a ayahuasca. Entre interação e transação, os encontros põem assim em relação, e às vezes em conflito, duas expectativas diferentes porém complementares. Para o amazônico, indígena ou mestiço, o gringo em busca da ayahuasca é um avatar do "Branco", doravante parceiro cliente e fonte de melhoria de suas condições materiais de vida segundo uma lógica de progresso econômico local. Em contrapartida, para os clientes da ayahuasca, o xamã e sua comitiva local aparecem como um recurso espiritual e terapêutico, contestando o ideal do progresso material.

Uma análise do "xamanismo" ao mesmo tempo como "categoria dialógica" (Langdon \& Santana de Rose, 2009), como "espelho do Ocidente que permite uma definição de Si e do Outro" (Hamayon, 2003), como "sistema de tradução" (Carneiro da Cunha, 1998) e como espaço de negociação constante de "co-saber" (Losonczy, 2002), recoloca em questão a idéia canônica que vê o xamanismo como um sistema fechado de representações e de práticas, metonímia de um pensamento indígena ontologizado. Isto implica em uma atenção crescente ao estudo dos processos interativos, dialógicos e negociados, discursivos e pragmáticos, capazes de engendrar novos agenciamentos representacionais e enquadramentos e sequências rituais.

Em uma paisagem etnográfica onde o "xamanismo" passa a funcionar como uma categoria que enquadra uma dialética de identidade e de alteridade (Hamayon, 2003), é importante colocar a questão de seu poder atuando enquanto categoria contextualmente ativa, que permite a atores para os quais esta noção é mutuamente inteligível reencontrarem-se em lugares diversificados e negociar o sentido e os objetivos de seus dizeres e fazeres. Construído sobre as pontes semânticas, discursivas e rituais produzidas por uma história complexa e inacabada de contatos, de compromissos e de traduções múltiplas, este campo multipolar desafia a imagem estereotipada do encontro entre um universo "indígena” e um universo "branco", diametralmente opostos.

Carneiro da Cunha vê o xamã como um "tradutor": seu aprendizado lhe permite encarnar a possibilidade de se mover entre diferentes pontos de vista, diferentes perspectivas, o que se supõe aumentar seu poder e sua capacidade de manipulação sobre sua comitiva humana e sobrenatural. Através de suas viagens de aprendizagem e experiências oníricas, ele consegue perceber e nomear, para a sua sociedade, as "figuras de alteridade", sejam elas espíritos, objetos ou práticas a ela estrangeiros. Seu reconhecimento social e a eficácia do seu poder resultam da qualidade e da pertinência de sua "tradução", trazida à tona em sua performance ritual. Segundo esta 
autora, tal competência individual de se mover e de agir como mediador e tradutor entre mundos diferentes explica a fácil internacionalização de práticas xamânicas vernáculas. Assim, a interpretação recente dos efeitos visionários facilitados pelo consumo da ayahuasca em termos de "busca espiritual" ou de "viagem às profundezas de si mesmo" pode ser compreendida como resultado de uma tradição performativa construída na interação entre um público novo e os xamãs mediadores.

Mobilizar a noção de tradução para apreender a natureza destas interações não implica na idéia de uma passagem linear entre uma linguagem e uma outra, entre uma visão do mundo e seu oposto. Associar a ela a noção de negociação de sentido permite interrogar o lugar das relações de força econômicas e políticas que enquadram o encontro dos atores e subentendem a manifestação de interesses divergentes. Esta negociação merece ser analisada como o produto instável e movente de um processo de tradução, entendido como o resultado sempre provisório de um vai-e-vem entre o "Eu" e o "Outro", o centro e a periferia, o rico e o pobre, o próximo e o distante.

Abordar o xamanismo como um campo multipolar de tradução abre caminho a uma análise dos fenômenos de internacionalização de discursos e práticas rituais vernáculas centradas nas continuidades e descontinuidades históricas e espaciais. A ayahuasca aparece como o pivô (turning point) deste campo por sua capacidade de atravessar o espaço e o tempo, graças ao fato de que ela continua a ser representada e interpretada como uma entidade dotada de agência, seja esta terapêutica, jurídica, política, ecológica ou patrimonial.

Tradução: Alice P. Cidade da Silva

Recebido em 3 de outubro de 2010

Aprovado em 5 de novembro de 2010

Anne-Marie Losonczy é professora da École Pratique des Hautes Études (Sorbonne) em Paris e da Université Libre de Bruxelles, e membro do Institut de Recherches Interdisciplinaires sur le Social (IRIS-CNRS-EHESS). Silvia Mesturini é colaboradora do Laboratoire d'Anthropologie des Mondes Contemporaines da Université Libre de Bruxelles (LAMC-ULB). As duas autoras tem realizado conjuntamente pesquisas, sob uma ótica comparativa, sobre a recomposição de práticas rituais ditas "xamânicas" em novos meios sociais urbanos. Endereço eletrônico: <alosonczy1956@gmail.com>. 


\section{Notas}

1. A receita da decoç̧ão correspondente a este nome contém proporções variáveis de Banisteriopsis Caapi ou Banisteriopis Inebrians e de Psychotria Carthaginensis ou Psychotropia Viridis, às quais outras plantas são acrescentadas de acordo com a receita de cada xamã. Seu uso é verificado entre numerosos grupos ameríndios da Amazônia ocidental, mas desde o começo do século XX ele ultrapassa as fronteiras étnicas disseminando-se entre populações amazônicas de origens diversas.

2. Este texto se apóia em duas experiências de observação e de participação nos rituais de consumo da ayahuasca em Bogotá e em Medellín (Colômbia) em 2006-2007 por AnneMarie Losonczy e em uma pesquisa multissituada de 18 meses em vários países da América Latina acompanhada de investigações pontuais em vários países europeus entre 2004-2009, por Silvia Mesturini, cujos resultados foram apresentados em uma tese defendida com sucesso em setembro de 2010, bem como sobre múltiplas discussões entre as duas autoras. Uma versão reelaborada deste texto foi publicada em francês sob o título "Pourquoi l'ayahuasca? Autour de l'expansion d'une pratique rituelle amérindienne”, em Archives des Sciences Sociales des Religions, 153, 2011, Editions de l'EHESS, Paris.

3. Http://www.shamanism.org

4. Este sistema, resultante da exploração do caucho na Amazônia, configura uma cadeia de dependência econômica e social. Os colonos brancos, obtendo do Estado os direitos de exploração de recursos florestais sobre um território determinado e possuindo os contatos comerciais nacionais e internacionais e os transportes, recrutam trabalhadores de origem amazônica ou de outras regiões aos quais eles fornecem ferramentas e víveres a serem pagos com trabalho. Isto cria um sistema de dívida permanente acorrentando indefinidamente o trabalhador a seu empregador. Este sistema continuou a sustentar até recentemente um modelo social regional de extrema assimetria, que uma literatura sociológica conceitualiza para a Amazônia brasileira em termos de sistema paternalista. (Geffray, 1992; Santos Araujo, 1993). 


\section{Referências bibliográficas}

ALEXIADES, Miguel N. (ed). 2009. Mobility and Migration in Indigenous Amazonia. Contemporary Ethnoecological Perspectives. Berghahn Books.

CALAVIA SAEZ, Oscar. 2009. "A vine Network”. Ms.

CARNEIRO, Henrique. 2005. “A odisséia psiconáutica: a história de um século e meio de pesquisas sobre plantas e sustancias psicoativas”. In: Labate, B. e Goulart, S. (orgs.), O uso ritual das plantas de poder. Campinas: Mercado das Letras/FAPESP.

CARNEIRO DA CUNHA, Manuela. 1998 . "Pontos de vista sobre a floresta amazónica: xamanismo e tradução”. Mana, 4(1):7-22.

CORTES, Geneviève e Laurent FARET. 2009. "La circulation migratoire dans l'ordre des mobilités”. In: G. Cortes e L. Faret, Les circulations transnationales. Paris: Armand Colin.

DIAS, Walter Junior. 1992. “O Imperio de Juramidam nas batalhas do Astral - Uma cartografia do imaginario no culto ao Santo Daime”. Dissertação de mestrado em Ciências Sociais, PUC-SP.

DOBKIN DE RIOS, Marlène. 1972. Visionary Vine. Hallucinogenic Healing in the Peruvian Amazon. San Francisco: Chandler Publishing Co.

ELIADE, Mircea. 1983, (1951). Le chamanisme et les techniques archaïques de l'extase. Paris: Payot.

GHASARIAN, Christian. 2002 .Santé alternative et New Age à San Francisco”. In : R. Massé e J. Benoist (eds), Convocations thérapeutiques du sacré, Paris : Médecines du Monde, Karthala. pp. 143-163.

GOW, Peter. 1991. Of Mixed Blood: kinship and history in Peruvian Amazonia. Oxford: Clarendon Press.

GOW, Peter. 1993. "Gringos and Wild Indians. Images of history in Western Amazonian culture”. L'Homme 126-128, XXXIII (2-4):327-347.

GOW Peter. 1999. "River People : Shamanism and History in Western Amazonia" in: N. Thomas \& C. Humphrey (eds.), Shamanism, History and the state. Ann Arbor: The University of Michigan Press.

GROISMAN, Alberto. 1996. "Santo Daime: notas sobre a 'luz xamânica' da Rainha da Floresta”. In: E. J. Langdon (org.), Xamanismo no Brasil: novas perspectivas. Florianopolis: Editora da UFSC.

GROISMAN, Alberto. 1999. "Eu venho da floresta. Um estudo sobre o contexto simbólico do uso do Santo Daime”. Florianopolis: UFSC.

HAMAYON, Roberte. 2003. "Introduction à Chamanismes. Réalités autochtones, réinventions occidentales”. Diogène. Paris: PUF. pp. 7-54. 
HAMMER, Olav. 2001. Claiming Knowledge. Strategies of epistemology from theosophy to the New Age. Leiden: Brill.

HUXLEY, Aldous. 1954. The doors of perception. New York: Harper \& Row.

JOHNSON, Paul. 2003. "Shamanism from Ecuador to Chicago: a case study in New Age ritual appropriation”. In: G. Harvey (ed.), Shamanism. A Reader. New York \& London: Routledge.

LA BARRE, Weston. 1971. The Peyote Cult. New York: Schocken Books.

LANGDON, Esther Jean. 2005. "Prefacio”. In B. Labate e S. Goulart (orgs.), O uso ritual das plantas de poder. Campinas: Mercado das Letras/FAPESP.

LANGDON, Esther Jean. 2008. "New Perspectives of Shamanism in Brazil: Shamanism and Neoshamanism as Dialogical Categories”. Trabalho apresentado no Seminário Permanente de Etnografia Mexicana, Instituto Nacional de Antropologia e História, México..

LANGDON, Jean \& Isabel SANTANA DE ROSE. 2009 . "Diálogos (neo)xamânicos: encontros entre os Guarani e a ayahuasca”. Ms.

LIMA DA SILVA, Raquel. 2002 . "Naturaleza, Rainha da Floresta e Indianidade: o caso da igreja do Santo Daime entre os indios Apurina da aldeia Camicua», Monografia de Graduação em Ciências Sociais, Universidade Federal do Acre.

LOSONCZY, Anne-Marie. 2002. "De l'énigme réciproque au co-savoir et au silence. Figures de la relation ethnographique” In : De l'ethnographie à l'anthropologie réflexive. Nouveaux terrains, nouvelles pratiques, nouveaux enjeux. Paris: Armand Colin. pp. 91-103.

MASTERS, R.E.L. \& J. HOUSTON. 1970. LSD, Marihuana,Yoga and Hypnosis, Chicago: Aldine Publishing Company.

McRAE, Edward. 1992. Guiado pela lua. Xamanismo e uso ritual da ayahusca no culto do Santo Daime. São Paulo: Editora Brasiliense.

Mc RAE, Edward. 2000. El Santo Daime y la espiritualidad brasileña. Quito: Abya-Yala.

MESTURINI, Silvia. 2010. "Espaces chamaniques en mouvement. Itinéraires vécus et géographies multiples entre Europe et Amérique Latine”. Thèse de Doctorat, Université Libre de Bruxelles, Belgique.

NARANJO, Claudio. 1978. Conscousness and Creativity. San Diego: Ross Books, San Diego.

RUCK, Carl A., BIGWOOD, Jeremy, STAPLES, Danny, OTT, Jonathan \& R. WASSON, Gordon. 1979. "Entheogens". Journal of Psychoactive Drugs, 11 (1-2).

SOIBELMAN, Tania. 1995. "My Father and My Mother: Show me your Beauty. Ritual Use of Ayahuasca in Rio de Janeiro". Master of Social and Cultural Anthropology, Institute of Integral Studies, California.

TAUSSIG Michael. 1986. Shamanism, Colonialism and the Wild Man. A Study in Terror and Healing. Chicago: University of Chicago Press. 
Resumo

$\mathrm{O}$ argumento deste texto se baseia em observações convergentes que vêm mostrando como, para além dos usos locais e regionais, a bebida conhecida como ayahuasca funciona hoje, nas redes globalizadas de sua circulação, ao mesmo tempo como signo diacrítico e como núcleo de negociação e distribuição de sentido e legitimidade, reconfigurando simbolicamente as relações entre os atores na nova interface entre grupos indígenas locais e o mundo urbano, latino-americano ou internacional. Entender o sucesso contemporâneo da ayahuasca implica pois compreender a dinâmica entre continuidade e criações culturais e sociais emergentes que constitui a trama histórica e presente de contatos e adaptações mútuas entre diversos povos amazônicos de um lado e entre o mundo amazônico e seus visitantes, representantes de sucessivos poderes externos, de outro.

Palavras-chave: ayahuasca, xamanismo, contracultura, antropologia, patrimônio.

\section{Abstract}

This text is based on the premise that the ayahuasca beverage passed from local and regional use to circulation in a globalized network and argues that it now works as a diacritical sign and plays a critical part in negociating and reallocating meaning and legitimacy. Thus relationships between actors, in the new interface between local indigenous societies and Latin American and international worlds, are symbolically recomposed. To understand the contemporary success of ayahuasca implies grasping the dynamics between continuity and emerging cultural and social creations, which make up the web of historical and present-day contacts and adaptations between the diverse Amazonian peoples as well as between Amazonian peoples and successive external visitors and powers.

Keywords: ayahuasca, shamanism, counterculture, anthropology, heritage. 